\section{Psicologia Escolar \\ e Educacional}

\section{RELATO DE PRÁTICAS PROFISSIONAIS}

DOI: http://dx.doi.org/10.1590/2175-35392021237016

Localizador - e237016

\title{
OS DESAFIOS E AS ESTRATÉGIAS DA PSICOLOGIA ESCOLAR NO ENFRENTAMENTO DO BULLYING
}

\author{
Adinete Sousa da Costa Mezzalira ' ${ }^{\mathbb{D}}$; Thatyanny Gomes Fernandes ${ }^{1} \mathbb{D}$; Cyntia Maria Loiola dos Santos ${ }^{1} \mathbb{D}$
}

\section{RESUMO}

Este é um relato das atividades práticas de um projeto extensionista realizado em uma escola Estadual de Ensino Fundamental em Manaus (AM), tendo como objetivo problematizar com os professores a temática do bullying na escola. Foram desenvolvidas quatro oficinas: (1) Identificando a concepção de bullying no cotidiano escolar; (2) 0 que as pesquisas acadêmicas têm falado sobre o bullying?; (3) Como combater a dinâmica do bullying em contexto escolar?; (4) Construindo coletivamente ações de enfrentamento ao bullying. Os principais resultados encontrados foram: (a) ações de enfrentamento à violência dirigidas, principalmente, aos sujeitos envolvidos na situação; (b) relação estreita entre bullying e preconceito; (c) judicialização do processo educativo; e, (d) ação coletiva como prática crítica para o enfrentamento do bullying. Diante disso, concluímos que o psicólogo escolar deve problematizar e possibilitar o debate sobre o bullying e suas formas de intervenção no espaço educativo.

Palavras-chave: psicologia escolar; bullying; professores; ensino fundamental

\section{The challenges and strategies of School Psychology facing bullying}

\begin{abstract}
This is a report of the practical activities of an extension project carried out in a State Elementary School in Manaus (AM), aiming to problematize with teachers the theme of bullying in the school context. Four workshops were developed: (1) Identifying the concept of bullying in everyday school life; (2) What academic research has said about bullying?; (3) How to combat the dynamics of bullying in a school context?; (4) Collectively building actions to fight bullying. The main results found were: (a) actions to confront violence aimed mainly at the subjects involved in the situation; (b) close relationship between bullying and prejudice; (c) judicialization of the educational process; and, (d) collective action as a critical practice for dealing with bullying. Therefore, we conclude that the school psychologist must discuss and enable the debate about bullying and its forms of intervention in the school environment.
\end{abstract}

Keywords: school psychology; bullying; teachers; elementary school

\section{Los desafíos y las estrategias de la Psicología Escolar en el enfrentamiento del bullying}

\section{RESUMEN}

Este es un relato de las actividades prácticas de un proyecto extensionista realizado en una escuela Estadual de Enseñanza Básica en Manaus (AM), teniendo como objetivo problematizar con los profesores la temática del bullying en el contexto escolar. Se desarrollaron cuatro talleres: (1) Identificando la concepción de bullying en el cotidiano escolar; (2) ¿Lo qué las investigaciones académicas han dicho sobre el bullying?; (3) ¿Cómo hacer frente a la dinámica del bullying en contexto escolar?; (4) Construyendo colectivamente acciones de enfrentamiento al bullying. Los principales resultados encontrados fueron: (a) acciones de enfrentamiento a la violencia dirigidas, principalmente, a los sujetos involucrados en la situación; (b) relación estrecha entre bullying y prejuicio; (c) judicialización del proceso educativo; y, (d) acción colectiva como práctica crítica para el enfrentamiento del bullying. Delante de eso, se concluye que el psicólogo escolar debe problematizar y posibilitar el debate sobre el bullying y sus formas de intervención en el espacio educativo.

Palabras clave: psicología escolar; bullying; profesores; enseñanza básica

1 Universidade Federal do Amazonas-Manaus-AM-Brasil; adinetecosta@hotmail.com; fernandesthatyanny@gmail.com; cyntia. loiola@yahoo.com.br 


\section{INTRODUÇÃO}

Atualmente, uma das formas de violência discutida com maior ênfase nas mídias e no cotidiano escolar é o bullying. Diversos estudos têm sido realizados sobre esse tema, o que acabou popularizando esse termo, embora ainda existam muitas dúvidas a respeito do verdadeiro significado dessa palavra. De acordo com Braga e Lisboa (2014), pelo fato de não possuir tradução para a língua portuguesa, o termo tem sido comumente utilizado para se referir aos "maus-tratos entre os pares" e "intimidação", o que reduziria a complexidade do fenômeno.

As primeiras pesquisas sobre bullying escolar começaram na Suécia, na década de 1970, e os diversos estudos sobre a temática têm retratado esse constructo a partir de três características principais: (a) perseguição intencional com o objetivo de causar danos físicos ou psicológicos, (b) atitude repetitiva e (c) relação desigual de poder (Oliveira-Menegotto, Pasini, \& Levandowski, 2013). Mas esse entendimento do fenômeno tem sido questionado por muitos pesquisadores. Para Francisco e Libório $(2013,2015)$, essa compreensão simplista - de caráter individualista, pautado na culpabilização e na vitimização dos envolvidos no processo - tem ocasionado equívocos nas formas de enfrentamento do bullying no contexto escolar. Segundo esses autores, toda e qualquer manifestação de violência em contexto escolar tem sido, frequentemente, entendida como bullying e isso é algo preocupante porque outras formas de violência têm sido reduzidas a esse conceito, como é o caso da homofobia, da misoginia, do racismo, entre outros.

É certo que podemos encontrar algumas pesquisas interessadas em analisar as causas do bullying a partir de fatores sociais, econômicos e particulares, mas essas análises, em sua maioria, têm ocorrido de forma fragmentada. Os pesquisadores Crochík et al. (2014) nos alertam para o fato de que o bullying tem sido comumente compreendido como um problema pontual, dependente da escola e/ou da família e/ou do indivíduo, sem reconhecer a ligação entre a totalidade social, institucional e individual. Para os referidos autores, temos o compromisso de entender o bullying escolar como um reflexo das relações sociais estruturadas na sociedade.

Dessa maneira, não é possível afirmar que a causa é apenas social e tampouco individual, uma vez que ambas se atravessam mutuamente. Diante da tentativa de sensibilizar a escola para a necessidade de práticas críticas e contextualizadas de enfrentamento do bullying a partir de uma perspectiva social, foi pensada uma ação extensionista universitária em uma Escola Estadual de Ensino Fundamental na cidade de Manaus (AM), com alunos na faixa etária de 11 a 15 anos. Tendo como objetivo problematizar com os professores a temática do bullying no contexto escolar.

\section{PROPOSTA DE ATUAÇÃO PARA O PSICÓLOGO ESCOLAR}

A equipe responsável pela realização da atividade extensionista contou com estudantes de pedagogia e psicologia e profissionais da psicologia. As atividades na escola foram desenvolvidas por meio de oficinas, uma vez por semana, com duração de duas horas em média e tiveram a participação de oito professores (as).

As oficinas se desenvolveram norteadas pelo princípio interativo-dialógico, segundo o qual, o diálogo horizontalizado e a construção conjunta das práticas ocupam lugar central. Para Freire (1987) o mundo, enquanto humano, histórico e cultural, é construído pela intercomunicação dialógica. Nessa perspectiva, todos os sujeitos têm o direito à comunicação e de serem reconhecidos como senhores de sua voz. Por isso, elaborar nossas oficinas ouvindo os professores foi essencial para o reconhecimento de suas vozes, seus posicionamentos e o modo de intervenção a ser trabalhado em conjunto com a equipe extensionista. Desse modo, na escola, foram realizadas quatro oficinas estruturadas a partir das seguintes temáticas: Oficina 1: Identificando a concepção de bullying no cotidiano escolar; Oficina 2: $O$ que as pesquisas acadêmicas têm falado sobre o bullying?; Oficina 3: Como combater a dinâmica do bullying em contexto escolar?; Oficina 4: Construindo ações de enfrentamento ao bullying.

\section{As oficinas}

\section{Oficina 1: Identificando a concepção de bullying no cotidiano escolar}

Esta oficina teve como objetivo apresentar o projeto e escutar as demandas e as opiniões de docentes sobre o bullying. Para isso, organizamos uma roda de conversa que foi norteada por algumas questões centrais: (a) Vocês têm interesse em dialogar sobre bullying? (b) Quais são os motivos que impulsionam a ter interesse ou não nessa temática? (c) Como são as intervenções diante de situações de bullying em contexto escolar?

Em geral, os profissionais mostraram-se entusiasmados em dialogar criticamente sobre o assunto em virtude da ausência formativa voltada ao tema proposto. Considerando o princípio dialógico, a equipe extensionista e os/as educadores/as começaram a problematizar a dinâmica do bullying e expuseram cenas cotidianas que serviram como auxílio para o diálogo e o entendimento de como têm sido as ações e as percepções da escola diante deste fenômeno.

Com base em uma história compartilhada por uma professora e a aceitação de seu argumento por parte de alguns educadores, pudemos verificar a seguinte concepção de violência: "O problema é que hoje tudo vira motivo de discussão, isso é normal, quem nunca foi chamado de baleia, ou Olívia Palito na escola? Eu mesma era apelidada e nem por isso fiquei traumatizada". 
As histórias compartilhadas ajudaram a equipe a problematizar as perseguições constantes e repetitivas, interligando-as ao preconceito, bem como auxiliaram sobre o impacto da banalização e da naturalização dos comportamentos violentos na escola. Embora houvesse consciência sobre a necessidade do debate em torno da questão que envolvia violência, principalmente, o bullying, ainda era comum nos depararmos com o desmerecimento e a invisibilidade do fenômeno, quando os casos eram identificados na escola como corriqueiros ou de brincadeiras da idade.

Uma professora compartilhou a sua estratégia, explicou que se utiliza de ações punitivas e, quando necessário, busca instâncias judiciais e policiais para conter atos violentos:

Comigo não fazem isso não, tem regras na minha aula, e quem não cumpre, tá fora. Eu falo pra eles: se quiserem estudar, eu tô aqui e se não quiserem, eu tenho vários ex-alunos que são delegados e policiais e mando levar tudinho.

Ao dirigirem as ações punitivas aos autores de violência, os professores acreditavam que o problema seria resolvido. Esse tipo de concepção de enfrentamento da violência direcionada aos sujeitos envolvidos nos atos violentos tem sustentado o argumento da entrada da polícia e do poder judiciário nas escolas, convocando-os a atender situações que poderiam ser mediadas por ações pedagógicas voltadas para o fortalecimento de relações sociais respeitosas dentro do contexto escolar. Diante disso, os pesquisadores Albino e Terêncio (2012) reivindicam uma mudança de olhar acerca do cenário punitivo e consideram precipitada a ação de delegar ao judiciário - que possui força estatal - uma ação interventiva na tentativa de resgatar conceitos elementares de vida em sociedade.

Oficina 2: 0 que as pesquisas acadêmicas têm falado sobre o Bullying?

Nesse encontro, o objetivo principal foi compartilhar com as/os docentes os estudos e as pesquisas acadêmicas advindas de especialistas das áreas que envolviam a temática bullying. Com o intuito de refletir sobre o bullying a partir de uma perspectiva psicossocial, promovemos uma atividade pensada a partir da leitura que fizemos dos trabalhos de Antunes e Zuin (2008) e de Francisco e Libório (2013), em que explicam a estreita relação entre bullying e preconceito, sob uma lógica dialética, que, ao mesmo tempo, os diferencia e associa.

Para a realização dessa atividade colocamos sobre a mesa várias imagens relacionadas ao tema. Solicitamos às/aos docentes a identificação de imagens que se configuravam como bullying e/ou preconceito. Nessa atividade, ficou evidente a dificuldade para classificar as situações ilustradas nas imagens como um ou outro fenômeno, o que oportunizou a discussão acerca da construção social do preconceito e sua implicação no fenômeno do bullying. Essa atividade com os/as educadores/as gerou o seguinte questionamento: haveria bullying em uma sociedade em que não houvesse preconceito?

Os pesquisadores Francisco e Libório (2013) têm mobilizado em seu trabalho uma reflexão sobre as práticas individualistas, preconceituosas, classistas e sexistas predominantes em nossa sociedade e disparadoras da ocorrência e manutenção do bullying nas escolas. Para esses autores, a visão inatista, imediatista e classificatória sobre o bullying tem cooperado para o entendimento de que cabe somente aos implicados nesse processo a resolução dos conflitos, como ocorre no relato de uma professora, "Eu não me meto não, mando parar. Quando continuam, eu entendo que vão resolver entre eles ou fora da escola".

Fica evidente que há uma relação muito estreita entre bullying e a proposta de enfrentamento. Por isso, precisamos instrumentalizar os/as docentes com base em conhecimentos advindos de pesquisas acadêmicas e de especialistas das áreas que envolvem essa temática sob uma perspectiva psicossocial.

Oficina 3: Como combater a dinâmica do bullying em contexto escolar?

A proposta desta oficina foi discutir com o grupo formas de enfrentamento dialogando acerca de situações que ocorrem no cotidiano escolar e considerando a seguinte questão: como enfrentamos o bullying? Para tanto, primeiramente, apresentamos para as/os docentes diversas gravuras relacionadas à vivência do bullying. Espontaneamente, os professores escolheram a sua imagem e pensaram em uma forma de enfrentamento para as situações ilustradas. As ações de enfrentamento trazidas pelos professores pautaram-se no diálogo, no respeito ao próximo e às diferenças e nas instâncias judiciais como forma de encaminhamento para casos considerados "extremos".

Por intermédio dessas propostas apresentadas, levamos o grupo a dois questionamentos: (a) Judicializar resolve os problemas de bullying no contexto escolar? (b) A lei é suficiente para resolver problemas oriundos da escola? Houve unanimidade das/dos docentes ao enfatizarem a lei e a justiça como únicas alternativas para solucionarem os conflitos escolares, atribuindo principalmente, à figura do policial a responsabilidade para mediar os conflitos escolares. Uma professora enfatiza que "a presença da polícia dentro da escola resolveria metade dos problemas de bullying e violência, os alunos teriam medo e se intimidariam".

Diante dessa realidade, tem-se instaurado nas escolas o que chamamos de judicialização do processo educativo. De acordo com Chrispino e Chrispino (2008), isso se caracteriza pela ação da Justiça no contexto educativo, ou seja, é a expansão judicial em território 
escolar, intervindo em situações que emergem do chão da escola e resultam em diversas tentativas de regular a vida discente e os comportamentos considerados "desviantes".

De modo geral, esse encontro foi muito importante, pois os/as docentes perceberam que romper com essa prática de judicializar a educação pode significar uma tentativa de resgatar a autonomia perdidas por eles, os atores principais do processo educativo.

Oficina 4: Construindo coletivamente ações de enfrentamento ao bullying.

Nesta atividade explicamos que a proposta final do projeto extensionista era a realização de uma ação coletiva que problematizasse a dinâmica do bullying envolvendo a comunidade escolar.

Desse modo, em conjunto, ficou acertado que cada professor/a e um membro da equipe extensionista ficariam responsáveis por desenvolver a atividade na sala de aula. Essa atividade contava com três procedimentos básicos: (1) apresentar o conceito de bullying; (2) dialogar sobre cenas de bullying na escola; e (3) pensar coletivamente sobre formas de enfrentar o bullying.

No primeiro momento, com o intuito de esclarecer e problematizar o processo de responsabilização, o/a docente estimulava reflexões sobre o bullying, compartilhando elementos básicos para a compreensão do fenômeno. Após as explicações sobre as dúvidas básicas advindas dos alunos, foi solicitado a eles que se dividissem em pequenos grupos para darmos início à segunda etapa da atividade.

Nesses pequenos grupos, receberam um balão cheio contendo uma imagem ilustrativa que poderia remeter a situações de bullying na escola. Quando estouravam o balão, os grupos compartilhavam a imagem e pensavam coletivamente sobre formas de enfrentamento. Após essa exposição, a turma construiu cartazes contendo reflexões, sugestões e desafios que se apresentam em situações de bullying. Esses cartazes foram espalhados nos corredores da escola, permitindo que todos os estudantes e professores/as tivessem acesso ao que foi produzido nas salas de aulas.

Encerramos a ação coletiva nos reunindo com os/as docentes para escutarmos as suas experiências durante a realização das atividades. Nessa ocasião, um dos professores enfatizou: "O projeto me ajudou a olhar para essas situações com outros olhos. Bullying é sério e não podemos encarar isso como brincadeira de criança".

Essa oficina corrobora a proposta sugerida pela pesquisa de Crochík et al. (2014), quando recomenda atividades em contexto escolar direcionadas para o entendimento do fenômeno do bullying, incluindo toda a escola e não apenas os envolvidos nessa forma de violência. Com base nas considerações dos professores, acreditamos que é possível transformar a escola em um lugar de encontros, de construção da formação crítica e de verdadeiro espaço para a ampliação dos modos de existência.

\section{CONSIDERAÇÕES FINAIS}

Com base nas experiências apreendidas por meio desse projeto, diante de episódios de violência - vistos como corriqueiros e sem importância - observamos nas falas iniciais dos educadores uma postura ora permissiva, ora rigorosa. Essa dualidade controversa das ações revela que o desconhecimento do fenômeno torna a escola um espaço vulnerável para o aparecimento e manutenção do bullying. É fato, contudo, que a prática de tal fenômeno não deve passar despercebida pelos profissionais da Educação. As escolas, segundo Francisco e Coimbra (2015), devem funcionar como espaços de proteção e emancipação da vida dos/das alunos/as. Precisam compartilhar conhecimentos que rompem com os estereótipos que sustentam relações preconceituosas e com a naturalização das situações de violência que podem contribuir para a intolerância e a perseguição entre os pares.

Por se um fenômeno psicossocial, é fato que o enfrentamento do bullying não se esgota em ações desenvolvidas apenas nas escolas, mas, segundo Francisco e Coimbra (2015), se a escola reconhecer a dinâmica da violência em suas diferentes manifestações e acreditar que essa dinâmica pode ser alterada, irá contribuir essencial e fortemente para a transformação das relações sociais em nossa sociedade. Por isso, em nossa ação na escola, trabalhamos o conceito de bullying na esfera social, sem desconsiderar a dimensão individual e institucional do fenômeno.

Argumentamos, por fim, que o psicólogo escolar pode e deve problematizar esse fenômeno com toda a comunidade escolar, envolvendo alunos, educadores e família, bem como, desenvolver ações nas escolas sobre a ineficácia da culpabilização dos sujeitos como os únicos responsáveis pelos episódios de bullying.

\section{REFERÊNCIAS}

Antunes, D. C.; Zuin, A. A. S. (2008). Do bullying ao preconceito: os desafios da barbárie à educação. Psicologia \& Sociedade, 20(1), 33-42.

Albino, P. L.; Terêncio, M. G. (2012). Considerações críticas sobre o fenômeno do bullying: do conceito ao combate e à prevenção. Revista Eletrônica do CEAF, 1(2).

Braga, L. L.; Lisboa, C. (2014). Estratégias de Coping para Lidar com o Processo de Bullying: Um Estudo Qualitativo. Revista Interamericana de Psicología/Interamerican Journal of Psychology, 44(2), 321-331.

Chrispino, Á.; Chrispino, R. S. P. (2008). A judicialização das relações escolares e a responsabilidade civil dos educadores. Ensaio: Avaliação e Políticas em Educação, 16(58), 9-30.

Crochík, J. L.; Silva, P. F.; Freller, C. C.; Alves, L. S. L.; Carrenho, A. C.; Dalenoga, G. V. (2014). Análise de concepções e propostas de gestores escolares sobre o Bullying. Acta 
Scientiarum. Education, 36(1), 115-127.

Francisco, M. V.; Libório, R. M. C. (2013). Até onde o bullying escolar se constitui como reflexo das relações sociais?. Anais do XI Congresso Nacional de Educação - EDUCERE, Curitiba, PR, Brasil, 28066-28078.

Francisco, M. V.; Coimbra, R. M. (2015). Análise do bullying escolar sob o enfoque da psicologia histórico-cultural.

Este artigo foi traduzido do inglês pelas autoras.
Estudos de Psicologia, 20(3), 184-195. https://doi. org/10.5935/1678-4669.20150020

Freire, P. (1987). Pedagogia do oprimido (18a ed.). Rio de Janeiro: Paz e Terra.

Oliveira-Menegotto, L. M.; Pasini, A. I.; Levandowski, G. (2013). O bullying escolar no Brasil: uma revisão de artigos científicos. Psicologia: Teoria e Prática, 15(2), 203-215.

Recebido: 22 de abril de 2020

Aprovado: 07 de outubro de 2020 